\title{
Acute coronary syndrome leading to revision of a co-morbid condition in a young man with arthritis
}

\author{
Svitlana Smiyan ${ }^{1}$, Roman Komorovsky ${ }^{1}$, Nazarij Tomashchuk ${ }^{2}$ \\ ${ }^{1} 2^{\text {nd }}$ Department of Internal Medicine, Ivan Horbachevsky Ternopil National Medical University, Ukraine \\ ${ }^{2}$ Department of Cardiac Surgery, Lviv Regional Hospital, Ukraine
}

\begin{abstract}
Although patients with rheumatoid arthritis (RA) may have an increased incidence of cardiovascular events, the development of coronary artery disease and of myocardial infarction at young age is rather uncommon. Herein, we report a case of a 26-year-old man without classical cardiovascular risk factors, but with a 2-year history of RA, who experienced recurrent episodes of angina-like chest pain. His electrocardiogram showed ST-elevation and T-wave inversion in anterior chest leads, and the patient was sent for coronary angiography, which revealed multivessel coronary artery disease. Subsequently, the patient underwent coronary artery bypass grafting. Closer analysis of the patient's history and of the laboratory findings led to revision of the diagnosis of RA: the patient was found to meet the classification criteria for systemic lupus erythematosus. Pitfalls of the classification criteria and the impact of the revised diagnosis on the patient's care are discussed.
\end{abstract}

Key words: rheumatoid arthritis, acute coronary syndrome, systemic lupus erythematosus, classification criteria.

\section{Introduction}

Acute coronary syndrome (ACS) in young adults (aged $\leq 35$ years), although relatively rare, almost always represents a diagnostic challenge as young patients, as compared with older ones, have broader etiology, other cardiovascular risk factors, and different clinical manifestations and outcomes [1, 2]. Although early atheromatous coronary artery disease remains one of the major causes of ACS in a young population [3], other important etiologies comprise non-atheromatous coronary artery disease (congenital coronary anomalies, small and medium vessel vasculitides/vasculitic syndromes, spontaneous dissections, myocardial bridging), hypercoagulable states (antiphospholipid syndrome - APLS, factor V Leiden mutation and other thrombophilias), substance abuse (recreational drug use, particularly cocaine and amphetamines, alcohol binge drinking) $[4,5]$.

In this context, patients with rheumatologic disorders represent a special risk group [6], typically combining multiple risk factors (vasculitis, secondary APLS [7], early [8] and accelerated [9] development of atheromatous lesions). The risk of coronary involvement in rheumatologic diseases depends on the clinical entity of the latter. For instance, in rheumatoid arthritis (RA), which is one of the most prevalent inflammatory rheumatologic disorders, as well as in ankylosing spondyloarthritis, it is relatively low as compared with primary systemic vasculitides or systemic lupus erythematosus (SLE) [10].

\section{Case report}

A 26-year-old man presented in October 2016 to our rheumatology clinic because of non-erosive polyarthritis with severely elevated acute phase reactants (erythrocyte sedimentation rate $73 \mathrm{~mm} / \mathrm{h}$, reference value: $<15 \mathrm{~mm} / \mathrm{h}$; C-reactive protein $25 \mathrm{mg} / \mathrm{l}$, reference value: $<5 \mathrm{mg} / \mathrm{l})$. This was preceded by a 2-year history of follow-up outside our clinic for "rheumatoid arthritis" (Table I), as well as a recent acute coronary syndrome (presumably, a myocardial infarction) (Fig. 1) due to multivessel coronary artery disease (Figs. 2 and 3) managed 
Table I. Timeline

\begin{tabular}{|c|c|}
\hline Time & Events \\
\hline Late 2014 & The patient first experienced pain in knee joints \\
\hline Early 2015 & $\begin{array}{l}\text { The patient started experiencing morning joint stiffness, swollen hands, dyspnea, gradual weight loss } \\
(\sim 15 \mathrm{~kg} \text { within } 1 \text { year). Rheumatoid arthritis was suspected and the patient initiated non-steroidal } \\
\text { anti-inflammatory drug treatment with a positive effect }\end{array}$ \\
\hline January 2016 & Hospitalization due to severe anemia \\
\hline February 2016 & $\begin{array}{l}\text { The patient was experiencing persistent arthralgias, subfebrile body temperature, and hair loss. Continu- } \\
\text { ous therapy with corticosteroids and non-steroidal anti-inflammatory drugs was initiated }\end{array}$ \\
\hline 1-2 March 2016 & $\begin{array}{l}\text { Repeated attacks of substernal chest pain at rest radiating to both arms, accompanied by fatigue and } \\
\text { diaphoresis. The patient did not seek medical care }\end{array}$ \\
\hline 3 March 2016 & $\begin{array}{l}\text { The patient presented to a local hospital. His ECG revealed T-wave inversion in anterior chest leads } \\
\text { (Fig. 1), echocardiography demonstrated multiple segmental wall motion abnormalities with depressed } \\
\text { systolic function (LVEF 35\%), and coronary angiography detected a multivessel coronary artery disease } \\
\text { (Fig. 2). The patient was medically stabilized }\end{array}$ \\
\hline 17 March 2016 & Coronary artery bypass grafting: SVG-OM, SVG-LAD, SVG-DA \\
\hline October 2016 & The diagnosis of "rheumatoid arthritis" was revised in favor of "systemic lupus erythematosus" \\
\hline February 2019 & $\begin{array}{l}\text { Last follow-up. The patient is being followed up yearly in an outpatient clinic. His left ventricular systolic } \\
\text { function has improved (LVEF 50\%). The patient is receiving DMARDs and has been in remission } \\
\text { for the past } 2 \text { years }\end{array}$ \\
\hline
\end{tabular}

$L V E F$ - left ventricular ejection fraction, OM - obtuse marginal artery, SVG - saphenous vein graft.

with coronary artery bypass grafting (CABG). At the surgeon's discretion, it was decided to use venous grafts, and not the left internal mammary artery, as the latter showed decreased pulsation (retrospectively this was attributed to manifestation of vasculitis). The patient's height was $170 \mathrm{~cm}$, weight $55 \mathrm{~kg}$, giving him a body mass index of $19 \mathrm{~kg} / \mathrm{m}^{2}$.

The described patient did not have any classical cardiovascular risk factors. Additional laboratory investigation showed the presence of anemia, leukopenia 3,000/ $\mu$ l, lymphopenia 1,000/ $\mathrm{\mu l}$, thrombocytopenia $140 \mathrm{~K} / \mu \mathrm{l}$, negative rheumatoid factor $(<10 \mathrm{IU} / \mathrm{ml}$, reference value: $<14 \mathrm{IU} / \mathrm{ml})$, negative A-CCP IgG $(<7 \mathrm{IU} / \mathrm{ml}$, reference value: $<17 \mathrm{IU} / \mathrm{ml})$, positive antinuclear antibodies test (ANA AAB $4.7 \mathrm{l} / \mathrm{ml}$, reference value: $<1 \mathrm{IU} / \mathrm{ml}$ ), positive anti-double stranded DNA test (ANA-dsDNA IgG $38 \mathrm{lU} / \mathrm{ml}$, reference value: $<14 \mathrm{lU} / \mathrm{ml}$ ), positive anticardiolipin antibodies (IgA $3.12 \mathrm{lU} / \mathrm{ml}$, reference value: < $1 \mathrm{lU} / \mathrm{ml}$; lgG $4.28 \mathrm{lU} / \mathrm{ml}$, reference value: < $1 \mathrm{IU} / \mathrm{ml}$; IgM $8.07 \mathrm{IU} / \mathrm{ml}$, reference value: $<1 \mathrm{IU} / \mathrm{ml}$ ), positive extractable nuclear antigen antibodies (ENA AAB $2.9 \mathrm{lU} / \mathrm{ml}$, reference value: < $1 \mathrm{IU} / \mathrm{ml}$ ), positive anti-SSA (Ro) $1: 100$ (reference value: $<1: 50$ ), anti-SSB (La) $1: 100$ (reference value: <1:50). Detailed history taking revealed the fact of photosensitivity.

Thus, the patient met the classification criteria for SLE according to the 1997 Update of the 1982 American College of Rheumatology (ACR) Revised Criteria [11] by having 5 criteria (photosensitivity, polyarthritis, hematologic disorders, immunologic disorders, positive antinu- clear antibodies) while $\geq 4$ criteria are required for the diagnosis.

He also met the Systemic Lupus International Collaborating Clinics (SLICC) [12] classification criteria by having 6 criteria (clinical criteria: photosensitivity, synovitis in $\geq 2$ joints, leukopenia; immunologic criteria: positive ANA, anti-DNA, antiphospholipid antibodies) while $\geq 4$ criteria, including at least 1 clinical and 1 laboratory criterion, are required. The patient also scored 23 points according to the new ACR/EULAR (European League Against Rheumatism) classification criteria for SLE [13] (Table II). Systemic lupus erythematosus activity index (SLEDAI) score was 18 (arthritis $=4$, increased DNA binding $=2$, thrombocytopenia $=1$, leukopenia $=1$, alopecia $=2$, vasculitis $=8$ ). This necessitated reassessment of the previous diagnosis of RA, and diagnosis of the patient with SLE and secondary APLS.

\section{Patient management and follow-up}

The diagnosis of SLE and subsequent administration of disease-modifying anti-rheumatic drugs, including hydroxychloroquine, systemic glucocorticoids and methotrexate according to current recommendations [14] along with anticoagulation with warfarin and low-dose acetyl salicylic acid, resulted in drug-induced remission (SLEDAI score 2 [alopecia]) and freedom from major adverse cardiac events that has been maintained for the past 2 years. According to our judgment, previous therapy which the patient was receiving for RA was limited by the presence of 


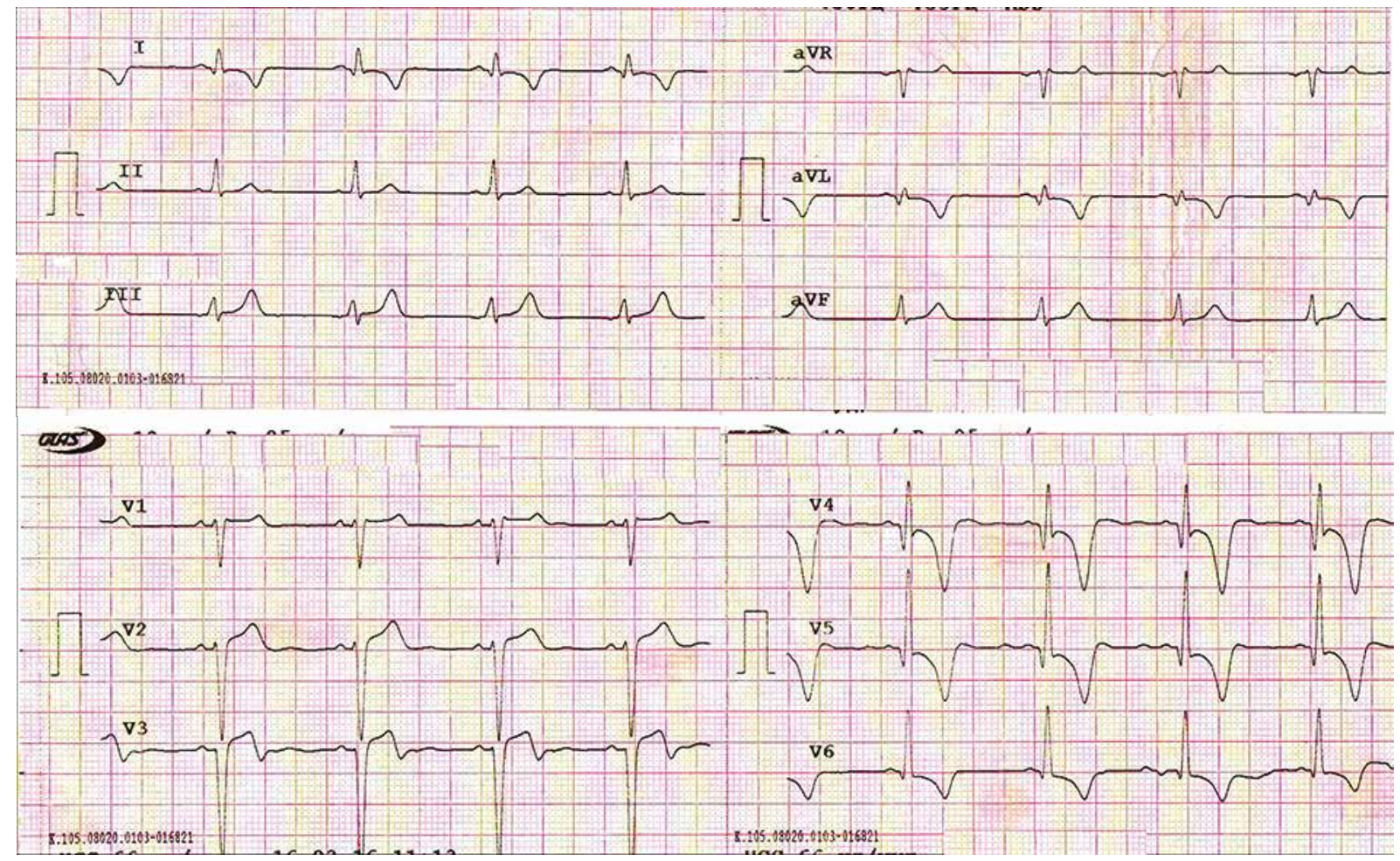

Fig. 1. Twelve-lead electrocardiogram demonstrating ST-elevation and deep inverted T-waves in anterior chest leads consistent with recent myocardial infarction.

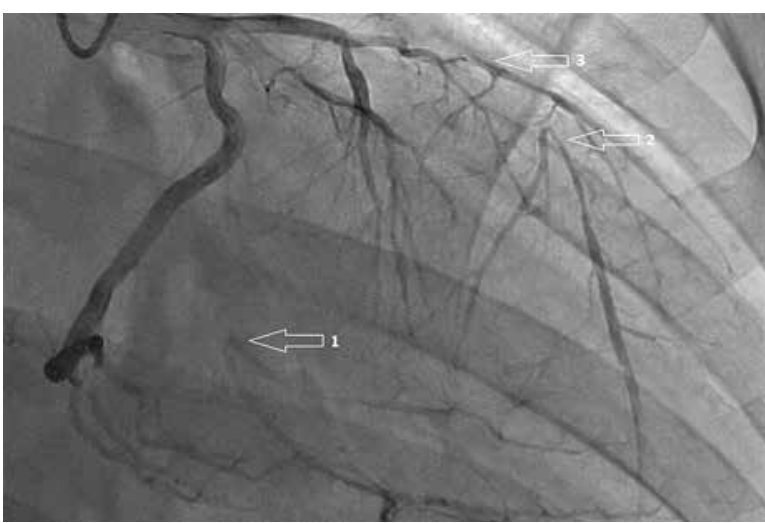

Fig. 2. Right anterior oblique view of the left coronary artery showing occluded (1) first obtuse marginal artery and (2) left anterior descending artery with retrograde collateral supply, and (3) critical stenosis of the diagonal branch.

anemia, and therefore adequate reduction of the disease activity at that time was not achieved.

\section{Discussion}

Systemic lupus erythematosus is a chronic autoimmune disease characterized by multisystem involve-

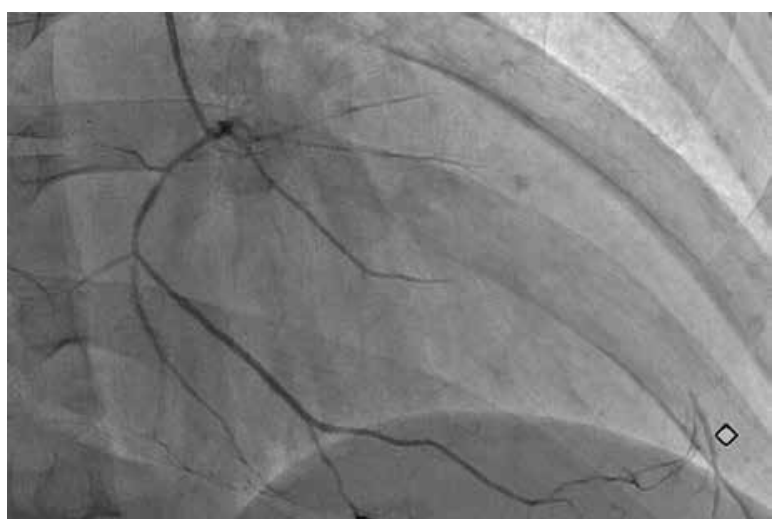

Fig. 3. Right anterior oblique view of the right coronary artery showing a diffusely narrowed right coronary artery providing collateral supply to distal left anterior descending artery.

ment. Any part of the heart may be affected, manifesting as myocarditis, pericarditis, conduction defects, valvular disease, or coronary thrombosis. Some patients also develop pulmonary hypertension. The pathogenesis of these variable manifestations is complex and still not completely understood $[6,15,16]$. With regard to the coronary artery disease, most of the available literature 
Table II. New 2018 ACR and EULAR criteria for classification of systemic lupus erythematosus [13]

\begin{tabular}{|c|c|c|c|}
\hline Clinical domains & Points & Immunologic domains & Points \\
\hline Constitutional domain & & \multicolumn{2}{|l|}{ Antiphospholipid antibody domain } \\
\hline Fever & 2 & \multirow{3}{*}{$\begin{array}{l}\text { Anticardiolipin IgG }>40 \mathrm{GPL} \\
\text { or anti- } \beta 2 \mathrm{GP} 1 \mathrm{IgG}>40 \mathrm{U} \\
\text { or lupus anticoagulant }\end{array}$} & \multirow[t]{3}{*}{2} \\
\hline Cutaneous domain & & & \\
\hline Non-scarring alopecia & 2 & & \\
\hline Oral ulcers & 2 & \multicolumn{2}{|l|}{ Complement proteins domain } \\
\hline Subacute cutaneous or discoid lupus & 4 & Low C3 or low C4 & 3 \\
\hline Acute cutaneous lupus & 6 & Low C3 and low C4 & 4 \\
\hline Arthritis domain & & \multicolumn{2}{|l|}{ Highly specific antibodies domain } \\
\hline $\begin{array}{l}\text { Synovitis in at least two joints or tenderness in at least } \\
\text { two joints, and at least } 30 \text { min of morning stiffness }\end{array}$ & 6 & $\begin{array}{l}\text { Anti-dsDNA antibody } \\
\text { Anti-Smith antibody }\end{array}$ & $\begin{array}{l}6 \\
6\end{array}$ \\
\hline \multicolumn{4}{|l|}{ Neurologic domain } \\
\hline Delirium & 2 & & \\
\hline Psychosis & 3 & & \\
\hline Seizures & 5 & & \\
\hline \multicolumn{4}{|l|}{ Serositis domain } \\
\hline Pleural or pericardial effusion & 5 & & \\
\hline Acute pericarditis & 6 & & \\
\hline \multicolumn{4}{|l|}{ Hematologic domain } \\
\hline Leukopenia & 3 & & \\
\hline Thrombocytopenia & 4 & & \\
\hline Autoimmune hemolysis & 4 & & \\
\hline \multicolumn{4}{|l|}{ Renal domain } \\
\hline Proteinuria $>0.5 \mathrm{~g} / 24 \mathrm{~h}$ & 4 & & \\
\hline Class II or V lupus nephritis & 8 & & \\
\hline Class III or IV lupus nephritis & 10 & & \\
\hline
\end{tabular}

sources either focus on atherosclerotic process or do not contain information on the nature of coronary involvement $[8,9,17]$.

Although traditional cardiovascular risk factors do not fully explain the increased cardiovascular risk in SLE, the elevated risk of ACS in these patients is considered to be associated with obesity, dyslipidemia, arterial hypertension, type 2 diabetes mellitus, sedentary lifestyle, male gender, smoking, advanced age, hyperhomocysteinemia, renal dysfunction, family history of coronary heart disease, as well as with the disease activity and presence of antiphospholipid antibodies. Antiphospholipid syndrome is associated with the incidence of myocardial infarction and angina pectoris of $5.5 \%$ and $2.7 \%$, respectively, and the incidence of coronary heart disease is relatively not high if compared with the incidence of cerebral and/or deep vein thromboses [18]. Acute coronary syndrome is an important complication in young patients with primary APLS without coronary heart disease risk factors, as well as in patients with SLE and secondary APLS. In some patients ACS/myocardial infarction developed before or shortly after the diagnosis of SLE $[19,20]$.

The relative roles of coronary thrombosis and of coronary atherosclerosis in patients with APLS and/or SLE have not yet been thoroughly studied [21]. On the other hand, the issue of percutaneous coronary interventions $(\mathrm{PCI})$ and CABG in patients with SLE and ACS needs further assessment because of equivocal data with regard to their appropriateness and effectiveness and increased associated risks [22].

The present case report highlights the difficulty of diagnosing SLE in a 26-year-old man who had been followed up by different specialists with a working diagnosis of seronegative "rheumatoid arthritis". Following the ACS, the patient's history and laboratory findings re- 
quired a further detailed analysis. Attention was drawn by significant hematologic disorders (anemia, leukopenia, lymphopenia, thrombocytopenia) and a history of photosensitivity. The first manifestation of SLE in this patient was persistent non-erosive polyarthritis with highly elevated acute phase reactants, and subsequently vasculitis (coronaritis) caused symptomatic multivessel coronary artery involvement requiring CABG.

From another standpoint, the patient did meet the ACR classification criteria for RA [23] (Table III). However, no consideration was given to alternative causes of arthritis in the light of hematological manifestations and a history of photosensitivity. Also, this case serves an example that especially in seronegative arthritis, which may formally fit the classification criteria of RA, the diagnosis of RA should be supported by imaging studies. Although younger age at disease onset and short disease duration have been associated with non-erosive RA in large cohort studies [24], a non-erosive disease associated with other extra-articular symptoms should raise the suspicion of SLE [25].

Indeed, rheumatic diseases are frequently characterized by multiple and variable manifestations, and classification criteria of these disorders have been primarily developed to identify homogeneous cohorts for clinical research [26]. Although the classification criteria are widely used in routine clinical practice for diagnostic purposes, the clinical diagnosis of many rheumatic diseases with multisystem involvement, including SLE, is still largely at the discretion of the attending physician.

The present case has some limitation because the diagnosis of coronary vasculitis was made based only on the clinical presentation without histopathological examination of the affected vessel being performed. Therefore, one cannot rule out another background of coronary artery involvement, e.g., APLS and premature accelerated atherosclerosis.

\section{Conclusions}

The present case illustrates how early onset of ACS and subsequently multivessel coronary artery disease led to revision of the previous diagnosis of concomitant RA, and finally allowed the diagnosis of SLE to be established. In young patients with ACS and without any classical cardiovascular risk factors, another underlying etiology of vessel involvement such as systemic connective tissue disease should be considered. In such cases the indications for interventional strategy should be carefully discussed in terms of risks and benefits. If early RA is diagnosed according to classification criteria, other causes of arthritis should be excluded in patients with
Table III. 2010 ACR/EULAR classification criteria for rheumatoid arthritis [23]

\begin{tabular}{|ll|}
\hline Criteria & Points \\
\hline Joint distribution (0-5) & 0 \\
\hline 1 large joint & 1 \\
\hline 2-10 large joints & 2 \\
\hline $1-3$ small joints (large joints not counted) & 3 \\
\hline $4-10$ small joints (large joints not counted) & 5 \\
\hline$>10$ joints (at least one small joint) & 0 \\
\hline Serology (0-3) & 2 \\
\hline Negative RF and negative ACPA & 3 \\
\hline High positive RF or high positive ACPA & 0 \\
\hline Symptom duration (0-1) & 1 \\
\hline$<6$ weeks & 0 \\
\hline$\geq 6$ weeks & 1 \\
\hline Acute phase reactants (0-1) & \\
\hline Normal CRP and normal ESR & \\
\hline Abnormal CRP or abnormal ESR &
\end{tabular}

$R F$ - rhe umatoid factor, ACPA - anti-citrullinated protein antibodies, CRR - C-reactive protein, ESR - erythrocyte sedimentation rate. The criteria marked in bold were detected in the patient. 2010 $A C R / E U L A R$ score $\geq 6$ = definite rheumatoid arthritis; patient's score $=7$, leading to misclassification of the patient.

extra-articular manifestations (i.e., leukopenia, lymphopenia, thrombocytopenia, anemia).

The authors declare no conflict of interest.

\section{References}

1. Davidson L, Wilcox J, Kim D, et al. Clinical features of precocious acute coronary syndrome. Am J Med 2014; 127: 140-144.

2. Tini G, Proietti G, Casenghi $M$, et al. Long-term outcome of acute coronary syndromes in young patients. High Blood Press Cardiovasc Res 2017; 24: 77-84.

3. Schoeneberger AW, Radovanovic D, Stauffer J-C, et al. Acute coronary syndromes in young patients: presentation, treatment and outcome. Int J Cardiol 2011; 148: 300-304.

4. Egred M, Viswanathan G, Davis GK. Myocardial infarction in young adults. Postgrad Med J 2005; 81: 741-745.

5. Kane GC, Keogh KA. Involvement of the heart by small and medium vessel vasculitis. Curr Opin Rheumatol 2009; 21: 29-34.

6. Chappuis S, Vogt P, Petitpierre S, et al. Atteintes cardiaques dans les connectivites: l'exemple du lupus érythémateux systémique. Rev Med Suisse 2010; 6: 804-811.

7. Capilla-Geay E, Poyet R, Brocq FX, et al. Infarctus du myocarde antérieur inaugural rélévateur d'un syndrome des antiphospholipides dans le cadre d'une polyarthrite lupique. Rev Med Interne 2016; 35: 371-374. 
8. Mattu A, Petrini J, Swencki S, et al. Premature atherosclerosis and acute coronary syndrome in systemic lupus erythematosus. Am J Emerg Med 2005; 23: 696-703.

9. Slimani N, Hakem D, Benoui Z, et al. Infarctus du myocarde et lupus érythémateux systémique: expression d'une athérosclérose accélérée. Angéiologie 2014; 65/66: 72-75.

10. Specker C. Das Herz bei rheumatologischen Erkrankungen. Internist 2007; 48: 284-289.

11. Hochberg MC. Updating the American College of rheumatology revised criteria for the classification of systemic lupus erythematosus. Arthritis Rheum 1997; 40: 1725.

12. Petri M, Orbai AM, Alarcón GS, et al. Derivation and validation of the Systemic Lupus International Collaborating Clinics classification criteria for systemic lupus erythematosus. Arthritis Rheum 2012; 64: 2677-2686.

13. Aringer M, Costenbader K, Brinks R, et al. OP0020 Validation of new systemic lupus erythematosus classification criteria. Ann Rheum Dis 2018; 77: 60.

14. Mosca M, Tani C, Aringer M, et al. European League Against Rheumatism recommendations for monitoring patients with systemic lupus erythematosus in clinical practice and in observational studies. Ann Rheum Dis 2010; 69: 1269-1274.

15. Miner JJ, Kim AH. Cardiac manifestations of systemic lupus erythematosus. Rheum Dis Clin North Am 2014; 40: 51-60.

16. Liu Y, Kaplan MJ. Cardiovascular disease in systemic lupus erythematosus: an update. Curr Opin Rheumatol 2018; 30: 441-448.

17. Kay SD, Poulsen MK, Diederichsen AC, Vosa A. Coronary, carotid, and lower-extremity atherosclerosis and their relationship in Danish patients with systemic lupus erythematosus. J Rheumatol 2016; 43: 315-322.

18. Cervera R, Piette JC, Font J, et al. Antiphospholipid syndrome: clinical and immunologic manifestations and patterns of dis- ease expression in a cohort of 1,000 patients. Arthritis Rheum 2002; 46: 1019-1027.

19. Urowitz MB, Gladman DD, Anderson NM, et al. Cardiovascular events prior to or early after diagnosis of systemic lupus erythematosus in the systemic lupus international collaborating clinics cohort. Lupus Sci Med 2016; 3: e000143.

20. Doyle R, Perry JC, Brennan J, Fahey J. Acute myocardial infarction as the presenting symptom of systemic lupus erythematosus. Pediatr Cardiol 2009; 30: 858-861.

21. Ito S, Hasuo T. Intravascular images of coronary stenosis with multiple channels in a patient with antiphospholipid syndrome: the optical coherence tomography findings. Intern Med 2017; 56: 1351-1356.

22. Budhun PK, Boodhoo KD, Long MY, Chen MH. Impact of antiphospholipid syndrome and/or systemic lupus erythematosus on the long-term adverse cardiovascular outcomes in patients after percutaneous coronary intervention. A systematic review and meta-analysis. Medicine (Baltimore) 2016; 95: e320.

23. Aletaha D, Neogi T, Silman AJ, et al. 2010 rheumatoid arthritis classification criteria. An American College of Rheumatology/ European League Against Rheumatism Collaborative Initiative. Ann Rheum Dis 2010; 69: 1580-1588.

24. Liao KP, Weinblatt ME, Cui J, et al. Clinical predictors of erosion-free status in rheumatoid arthritis: a prospective cohort study. Rheumatology (Oxford) 2011; 50: 1473-1479.

25. Amaya-Amaya J, Calixto O-J, Saade-Lemus S, et al. Does nonerosive rheumatoid arthritis exist? A cross-sectional analysis and a systematic literature review. Semin Arthritis Rheum 2015; 44: 489-498.

26. June RR, Aggarwal R. The use and abuse of diagnostic/classification criteria. Best Pract Res Clin Rheumatol 2014; 28: 921-934. 